\title{
Experimental Study on Low-Strength Similar-Material Proportioning and Properties for Coal Mining
}

\author{
Shaojie Chen, ${ }^{1,2}$ Hailong Wang, ${ }^{1}$ Junwen Zhang, ${ }^{3}$ Huilin Xing, ${ }^{2}$ and Huaiyuan Wang ${ }^{1}$ \\ ${ }^{1}$ State Key Laboratory of Mine Disaster Prevention and Control, Shandong University of Science and Technology, \\ Qingdao 266590, China \\ ${ }^{2}$ Centre for Geosciences Computing, School of Earth Sciences, The University of Queensland, Brisbane, QLD 4072, Australia \\ ${ }^{3}$ School of Mining Engineering, Heilongjiang University of Science and Technology, Harbin 150022, China
}

Correspondence should be addressed to Shaojie Chen; csjwyb@163.com

Received 14 May 2014; Revised 19 November 2014; Accepted 20 November 2014

Academic Editor: Guocheng Lv

Copyright (C) 2015 Shaojie Chen et al. This is an open access article distributed under the Creative Commons Attribution License, which permits unrestricted use, distribution, and reproduction in any medium, provided the original work is properly cited.

\begin{abstract}
Similar-material simulation test is an effective tool to study the practical problems in mining and civil engineering. This paper conducts an orthogonal study on low-strength similar materials comprising sand, fly ash, and plaster and analyses the sensitivity of the materials. The mechanical properties of the similar materials strongly depend on the proportioning ratio, and they can satisfy different similar-material simulation tests. The compression strength and elastic modulus of the similar material decrease as the sand-binder ratio or cement ratio increases. There are approximately linear relations between the compression strength/elastic modulus and sand-binder ratio and approximately power relations between the compression strength/elastic modulus and sandbinder ratio. Sensitivity analysis employing the range method shows that the effects of the cement ratio on the compression strength and elastic modulus are more obvious than the effects of the sand-binder ratio. Finally, one of similar materials is used in a simulation test of coal backfill mining.
\end{abstract}

\section{Introduction}

Some large-scale projects, such as the underground coal mining that reduce the strength of the strata and are subjected to deformation failure, are difficult to study on-site. Although these complex problems can be investigated through theoretical analysis and numerical modelling, most problems need to be investigated by conducting geomechanical simulation tests [1-5], such as similar-material simulations. A geomechanical simulation test is the representation of real physical objects, with the materials having mechanical properties similar to those of a prototype according to a certain proportionality relation. The model has all or most of the major characteristics of the prototype, and an experiment can be duplicated using the model in less time and at lower cost, and visual results can be obtained. To obtain results that are more convincing, the selected similar materials must have very similar physical and mechanical properties for the physical model and engineering prototype [6]. The materials and mixing ratio strongly affect the properties of the physical model, which is critical to the success of simulation tests.
With the help of similar-material simulation test, Gao et al. studied the time series system for induced caving of roof in continuous mining under complex backfill in ore body number 92 of Tongkeng Tin Mine [7]; Li et al. simulated the "domino effect" of the stope pillar unstable failure of gently inclined and medium thick phosphate rock under pillar and room caving [8] and the deformation behaviour of overburden rocks and mining pressure of the deep ore body of mining [9].

Moreover, Meguid et al. conducted physical modelling of tunnels in soft ground using a mixture of barite powder, sand, plaster powder, water, and liquid laundry detergent [10], and Fei et al. employed a temperature-analogue material to simulate the decreasing strength of the weak interlayer but did not obtain desired results [11]. A new similar material mixed using sand, barite powder, talc powder, cement, Vaseline, and silicone oil for fluid-solid coupling was developed by Li et al. to simulate the tunnel under Qingdao Kiaochow Bay in China [12], and the effects of the sand-binder ratio, binder proportions on similar materials of limestone was 
studied by Zuo et al. [13]. Zhang et al. developed a similar material of collapsible loess for simulation testing [14], and Hui et al. presented the similarity criterion analysis of goaf in a similar-material simulation [15], where the cement, sand, water, activated carbon, and coal powder were selected as the raw material to mix the coal similar material [16].

Although similar-material simulations have been widely employed, a new similar material is urgently required in the increasingly wide range of geomechanical engineering projects. For example, as coal resources are developed, there is an increasing focus on environmental protection. Backfill is increasingly carried out in coal mining to protect the environment and replace resources, and the backfill body has lower strength than the coal-bearing sedimentary rocks.

In order to find a new similar material to simulate rock mass with low strength in mining engineering, such as filling paste, this paper conducts an orthogonal study of low-strength similar materials comprising sand, fly ash, and plaster in a similar-material simulation test and analyses the sensitivity of the materials. One of similar materials is used in a simulation test of coal backfill mining, and the test result shows that the mixture of artificial materials is appropriate for the simulation test.

\section{Sample Preparation of Similar Material with Lower Strength}

The similar material with lower strength in this experiment is mixed with sand, fly ash, and plaster.

Considering that the similar material in the simulation model has lower strength, generally less than $120 \mathrm{kPa}$, similar materials with a larger sand-binder ratio and cement ratio are tested in an orthogonal study. To investigate the effect of the sand-binder ratio and cement ratio on mechanical properties of the materials, 16 groups of samples were tested for two factors and four levels (Table 1). The suitable similar material with lower strength can be mixed through a small adjustment to the mixing ratios. The quality concentration of the similar material in different levels is $80 \%$.

The samples of similar materials are standard cylindrical specimens with dimensions of $\Phi 50 \mathrm{~mm} \times 100 \mathrm{~mm}$. A PVC tube with diameter of $50 \mathrm{~mm}$ was cut into simple moulds each with length of $100 \mathrm{~mm}$, as shown in Figure 1. A vertical gap was cut in the middle of each mould to allow the removal of the standard sample. The original materials are clean river sand common gypsum and fly ash from a power plant. Appropriate proportions of aggregate and cementing materials were stirred evenly with a cement paste mixer, and water was then quantitatively added to the mixture. The mixture was put into the sample moulds and tamped. The standard specimens were obtained after three days. There were 48 samples in 16 groups, some of which are shown in Figure 2.

\section{Analysis of Uniaxial Compression Test Results}

3.1. Uniaxial Compression Test Results. Sixteen standard specimens were tested under uniaxial compression using
TABLE 1: Orthogonal study of similar materials.

\begin{tabular}{lcc}
\hline Level & \multicolumn{2}{c}{ Factor } \\
& Sand-binder ratio (A) & $\begin{array}{c}\text { Cement ratio } \\
\text { fly ash :gypsum (B) }\end{array}$ \\
\hline 1 & $6: 1$ & $8: 2$ \\
2 & $7: 1$ & $7: 3$ \\
3 & $8: 1$ & $6: 4$ \\
4 & $9: 1$ & $5: 5$ \\
\hline
\end{tabular}

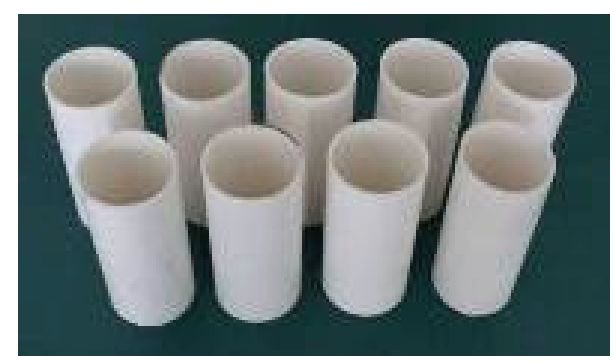

FIGURE 1: Moulds for making standard specimens.

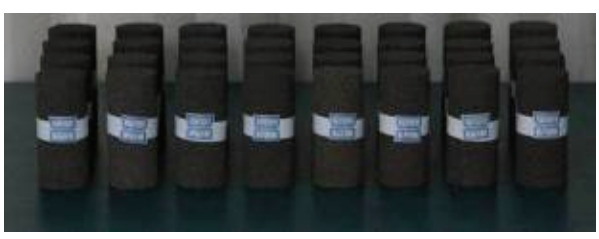

FIGURE 2: Standard specimens.

an AG-X250 electronic universal testing machine. The uniaxial compressive strength and elasticity modulus of similar materials with different mixing ratios are given in Table 2, where the number denoting the mixing ratio comprises three digits. When the number denoting the mixing ratio is " 682 ," for example, "6" represents the sand-binder ratio and " 82 " represents the cement ratio.

The uniaxial compressive strengths of similar material with different mixing ratios are between 28.542 and $100.407 \mathrm{kPa}$, and the elasticity moduli are between 813.918 and $4008.291 \mathrm{kPa}$, which are values that meet the requirements of most lower strength similar-material simulation tests [12]. At the same time, the required mixing ratio of the similar material can be selected from the results of the orthogonal experiment using the mechanical parameters of a single experimental model.

Typical failure specimens are shown in Figure 3, and stress-strain curves of similar-material specimens are presented in Figures 4 and 5.

3.2. Effects of the Sand-Binder Ratio and Cement Ratio on the Mechanical Properties. The variations in the strength of the similar materials with a change in the sand-binder ratio and cement ratio are shown in Figures 6 and 7. The strength of the similar materials clearly experiences a decrease as the sandbinder ratio or cement ratio increases. The relation between 
TABLE 2: Results of the orthogonal experiment on similar materials with different mixing ratios.

\begin{tabular}{|c|c|c|c|c|c|}
\hline Specimen number & Diameter/mm & Height/mm & $\begin{array}{c}\text { Number of } \\
\text { mixing ratios }\end{array}$ & $\begin{array}{c}\text { Uniaxial compressive } \\
\text { strength } / \mathrm{kPa}\end{array}$ & $\begin{array}{c}\text { Elasticity } \\
\text { modulus/kPa }\end{array}$ \\
\hline P11 & 46.58 & 102.32 & 682 & 51.93 & 1110.083 \\
\hline P12 & 46.16 & 101.16 & 673 & 58.388 & 1754.256 \\
\hline $\mathrm{P} 13$ & 46.82 & 103.48 & 664 & 78.818 & 3401.377 \\
\hline P14 & 46.64 & 102.70 & 655 & 100.407 & 4008.291 \\
\hline $\mathrm{P} 21$ & 46.38 & 100.52 & 782 & 44.100 & 961.323 \\
\hline $\mathrm{P} 22$ & 46.18 & 102.02 & 773 & 52.478 & 1698.07 \\
\hline $\mathrm{P} 23$ & 46.58 & 103.04 & 764 & 64.009 & 2629.804 \\
\hline P24 & 46.22 & 102.38 & 755 & 88.600 & 3862.366 \\
\hline P31 & 46.46 & 101.22 & 882 & 37.667 & 830.820 \\
\hline P32 & 46.64 & 102.66 & 873 & 43.958 & 1548.728 \\
\hline P33 & 46.52 & 102.42 & 864 & 53.935 & 2252.316 \\
\hline P34 & 46.50 & 102.48 & 855 & 72.092 & 3480.833 \\
\hline P41 & 46.58 & 101.54 & 982 & 28.542 & 813.918 \\
\hline $\mathrm{P} 42$ & 46.56 & 102.86 & 973 & 38.673 & 1311.437 \\
\hline $\mathrm{P} 43$ & 46.76 & 102.72 & 964 & 48.199 & 2133.269 \\
\hline P44 & 46.28 & 100.26 & 955 & 58.487 & 2941.296 \\
\hline
\end{tabular}

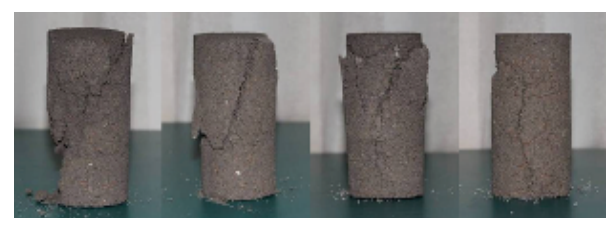

FIgURE 3: Typical failure specimens.

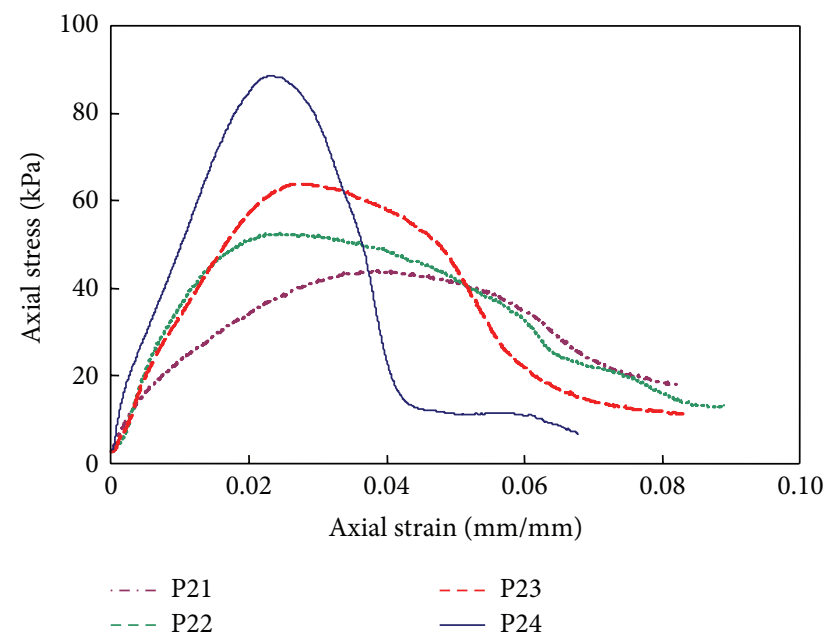

FIGURE 4: Stress-strain curves of material (sand-binder ratio of $7: 1$ ).

the sand-binder ratio and compression strength is linear; for example, the relation in the cement ratio case of $6: 4$ satisfies

$$
y=-14.227 x+186.6
$$

where $y$ is the compressive strength and $x$ is the sand-binder ratio.

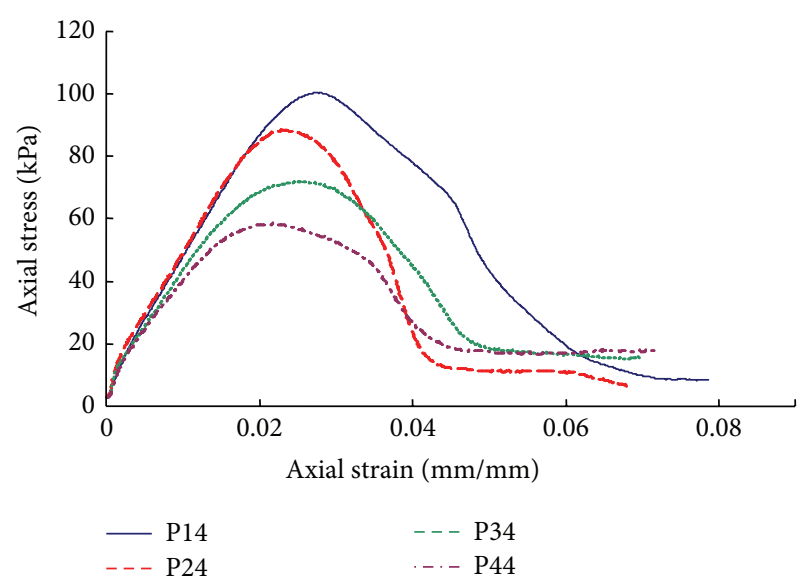

Figure 5: Stress-strain curves of material (cement ratio of $5: 5$ ).

The relation between the cement ratio and compression strength satisfies an exponential growth; for example, the relation in the sand-binder ratio case of $8: 1$ is

$$
y=68.303 x^{-0.462}
$$

where $y$ is the compressive strength and $x$ is the cement ratio.

The variations in the elasticity modulus of the similar material with a change in the sand-binder ratio and cement ratio are shown in Figures 8 and 9. Similar to the strength of the similar materials, the elasticity modulus of the material also experiences a reduction as the sand-binder ratio or cement ratio increases. A linear correlation between the sandbinder ratio and elasticity modulus is observed. In particular, the relation in the cement ratio case of $7: 3$ is

$$
y=-6.7665 x+99.123 \text {, }
$$

where $y$ is the elasticity modulus and $x$ is the sand-binder ratio. 


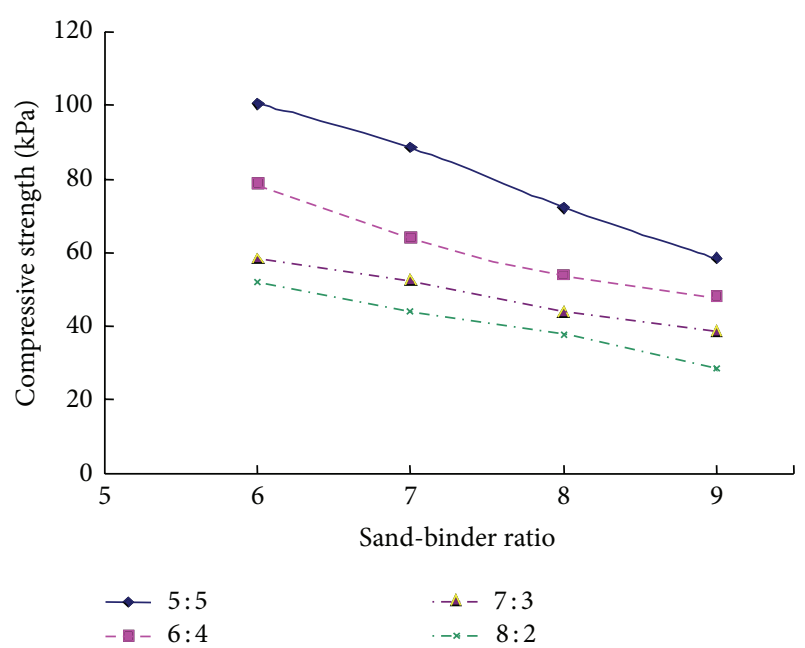

FIGURE 6: Effect of the sand-binder ratio on strength.

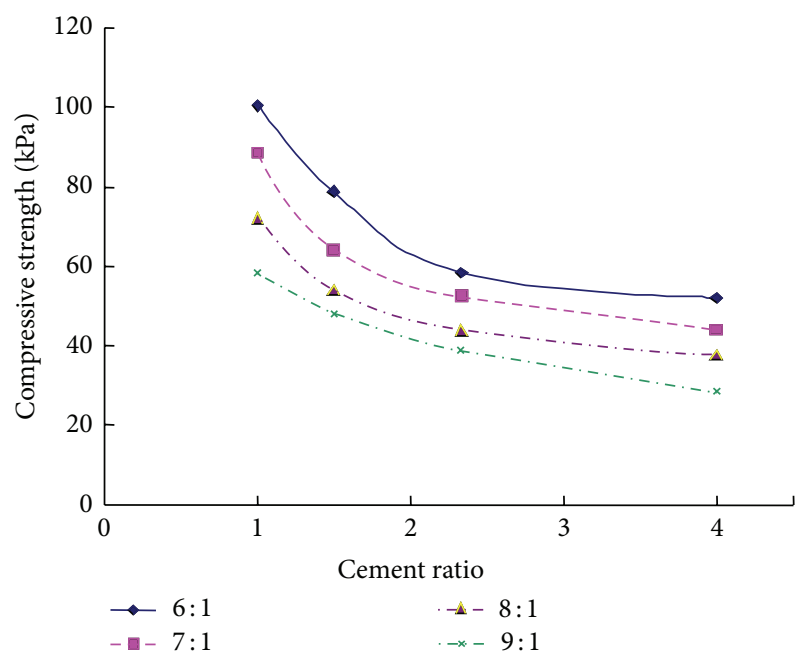

FIGURE 7: Effect of the cement ratio on strength.

The relation between the cement ratio and elasticity modulus satisfies an exponential growth; for example, the relation in the sand-binder ratio case $7: 1$ is

$$
y=3912.5 x^{-1.004}
$$

where $y$ is the elasticity modulus and $x$ is the cement ratio.

\section{Analysis of the Two Factors}

The mean and range of each factor at each level that affect the compressive strength and elasticity modulus of the similar materials are given in Table 3. The range of factor A (sandbinder ratio) is smaller than the range of factor $\mathrm{B}$ (cement ratio), and the effects of the cement ratio on the compression strength and elastic modulus are more remarkable than the effect of the sand-binder ratio.

To analyse the effect of various factors on the compressive strength and elasticity modulus intuitively, according to

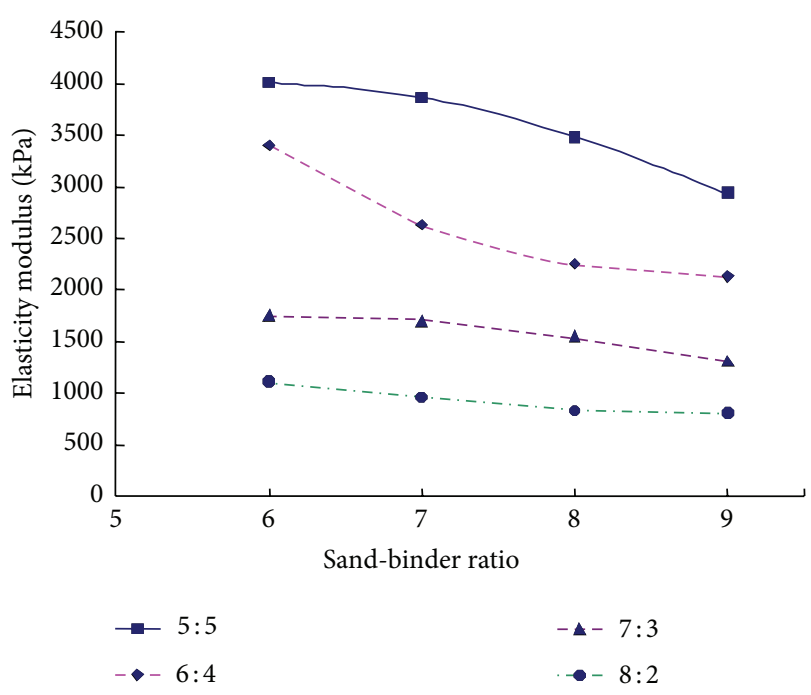

FIGURE 8: Effect of the sand-binder ratio on the elastic modulus.

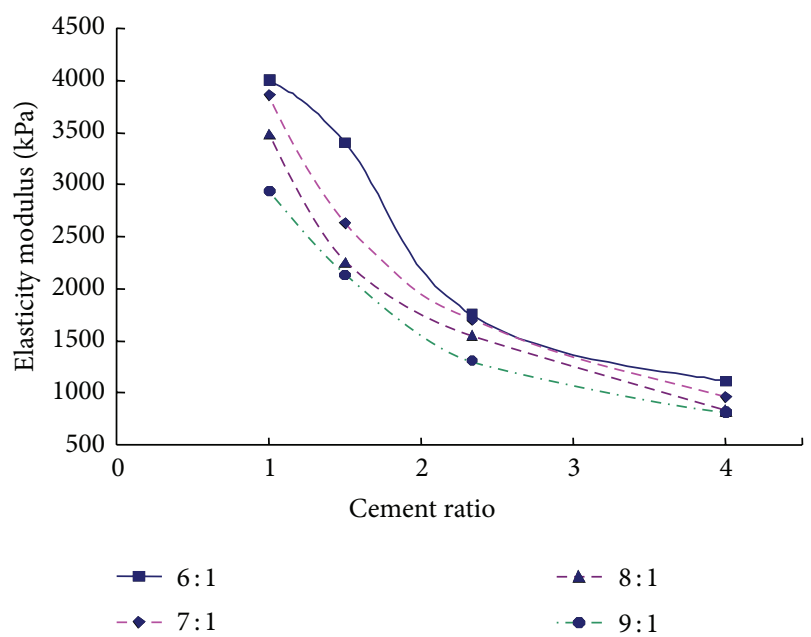

FIGURE 9: Effect of the cement ratio on the elastic modulus.

Table 3, the relationships between factors and mechanical parameters of the similar material are presented in direct analysis charts, as shown in Figures 10 and 11. Both the compression strength and elastic modulus of the similar material decrease as the sand-binder ratio or cement ratio increases.

\section{Lower Similar Material Used in Backfill Mining Simulation}

In this test, the referred prototype is the backfill mining of Daizhuang coal mine in China. If the low-strength similar material can simulate the deformation and supporting role of filling body and the overlying strata movement and failure mode are consistent with the practical project, the test can be seen as a success.

The aim of this test is to study the overlying strata movement and failure mode qualitatively. The scale effect between simulation experiment and practical engineering is 
TABLE 3: Range analysis.

\begin{tabular}{lccccc}
\hline & \multicolumn{2}{c}{ Compressive strength/kPa } & \multicolumn{3}{c}{ Elasticity modulus/kPa } \\
Level & Sand-binder ratio (A) & Fly ash : gypsum (B) & Level & Sand-binder ratio (A) & Fly ash : gypsum (B) \\
\hline 1 & 72.386 & 40.560 & 1 & 2568.502 & 929.036 \\
2 & 62.297 & 48.374 & 2 & 2287.891 & 1578.123 \\
3 & 51.913 & 61.240 & 3 & 2028.174 & 2604.192 \\
4 & 43.475 & 79.897 & 4 & 1799.980 & 3573.197 \\
Range & 28.911 & 39.337 & Range & 768.522 & 2644.161 \\
\hline
\end{tabular}

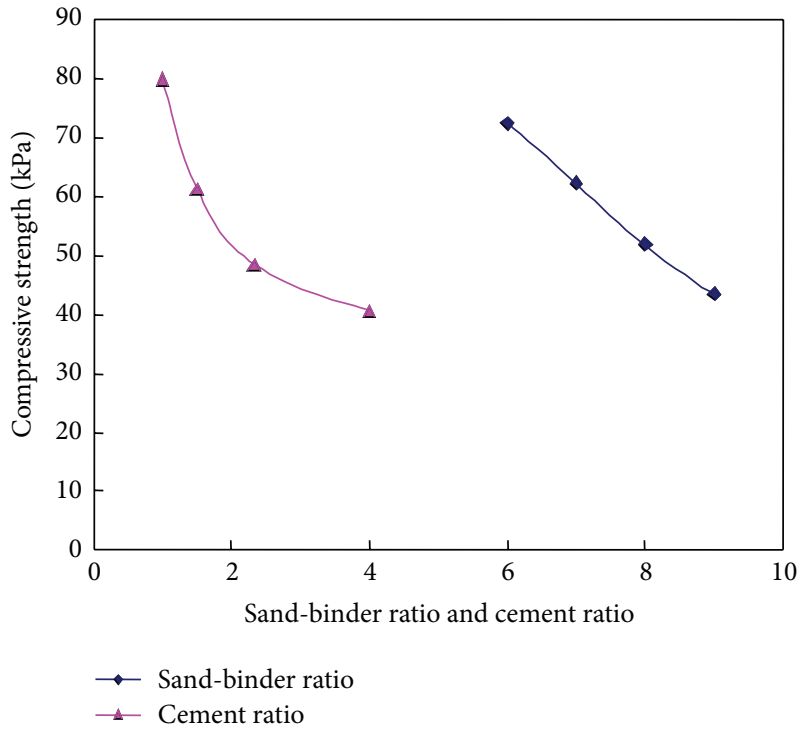

FIGURE 10: Sensitivity analysis of factors affecting strength.

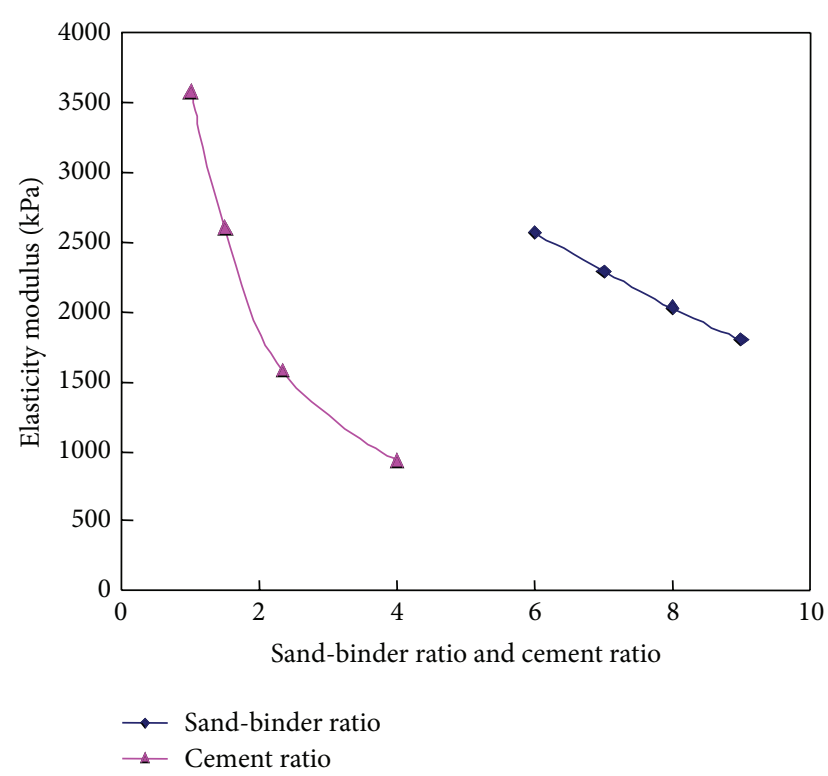

FIGURE 11: Sensitivity analysis of factors affecting the elastic modulus.

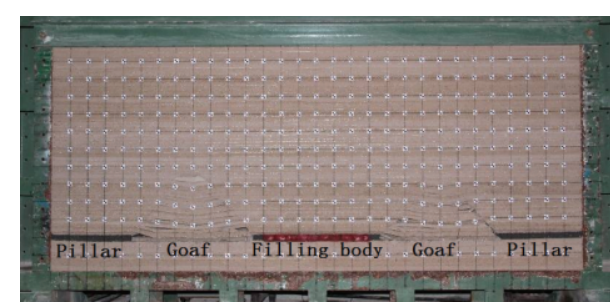

Figure 12: Similar-material simulation test of backfill mining.

not considered. According to the theory of similarity, similarmaterial simulation models must satisfy a series of similarity requirements in terms of geometry, physical-mechanical properties, boundary conditions, and initial stress conditions. The reduced scale of dimension in the simulation test is selected as 100. According to the similarity theory, the general law of similarity between the prototype parameters and the model parameters can be deduced. The reduced scale of volume-weight is selected as 1.5 and the reduced scale of stress is selected as 150 . The uniaxial compression strength of backfill paste obtained in site of Daizhuang coal mine is $5.436 \mathrm{MPa}$, and the strength of the similar material is $37.67 \mathrm{kPa}$. Thereby, the number of mixing ratios of the similar material is $8: 8: 2$ (see Table 2).

The two strip working faces are mined firstly in the experiment, and then the strip pillars are changed by the filling body. The simulation test of backfill mining is shown in Figure 12. After the strip pillars are changed, the equilibrium around the goaf is disrupted; then the overlying strata deform, move, and even damage. If it is not filled, the overlying strata will cave and break. After it is filled, the backfill pastes restrict the movement of roofs, and the overlying strata only bend and sink but not cave or break.

The backfill pastes have large deformation but control the overlying strata movement effectively, which are different from pillars. The experiment reproduced the real situation in field, and the low-strength backfill paste similar material played a right role in the simulation experiment.

\section{Conclusions}

(1) A new low-strength similar material was mixed from sand, fly ash, and plaster. The uniaxial compressive strengths of similar materials with different mixing ratios ranged from 28.542 to $100.407 \mathrm{kPa}$, 
and the elasticity modulus ranged from 813.918 to $4008.291 \mathrm{kPa}$. This similar material can meet the requirements of most similar-material simulation tests.

(2) The compression strength and elastic modulus of the similar material both decrease as the sand-binder ratio or cement ratio increases. A linear relation was found between the sand-binder ratio and compression strength of the material and between the sand-binder ratio and elastic modulus as well. The relation between the cement ratio and compression strength and that between the cement ratio and elastic modulus both satisfy an exponential growth.

(3) The sensitivities of the sand-binder ratio and cement ratio were analysed by employing the range method and the relationship between factors and parameters were studied using direct analysis charts where the factors affect the mechanical indexes. The effects of the cement ratio on the compression strength and elastic modulus are more remarkable than the effects of the sand-binder ratio.

(4) The effects of the sand-binder ratio and cement ratio on the mechanical properties of the materials were analysed in a uniaxial compression experiment but without consideration of the effects of material physical and chemical reactions among the sand, fly ash, and plaster, which will be studied in the future work.

(5) Based on the orthogonal test, one of similar materials is used in a simulation test of coal backfill mining. The experiment reproduced the real situation in field, and the low backfill paste similar material played a right role in the simulation experiment.

\section{Conflict of Interests}

The authors declare that there is no conflict of interests regarding the publication of this paper.

\section{Acknowledgments}

This study was supported by National Natural Science Foundation of China (nos. 51104094 and 51474134), Program for New Century Excellent Talents (NCET-13-0880), and Shandong Provincial Natural Science Foundation (ZR2013EEZ001).

\section{References}

[1] S. H. Kim, H. J. Burd, and G. W. E. Milligan, "Model testing of closely spaced tunnels in clay," Geotechnique, vol. 48, no. 3, pp. 375-388, 1998.

[2] D. N. Chapman, S. K. Ahn, D. V. L. Hunt, and A. H. C. Chan, "The use of model tests to investigate the ground displacements associated with multiple tunnel construction in soil," Tunnelling and Underground Space Technology, vol. 21, no. 3, p. 413, 2006.
[3] J. Lemaitre, "A continuous damage mechanics model for ductile fracture," Journal of Engineering Materials and Technology, vol. 107, no. 1, pp. 83-89, 1985.

[4] M. C. He, W. L. Gong, H. M. Zhai, and H. P. Zhang, "Physical modeling of deep ground excavation in geologically horizontal strata based on infrared thermography," Tunnelling and Underground Space Technology, vol. 25, no. 4, pp. 366-376, 2010.

[5] S. Jeon, J. Kim, Y. Seo, and C. Hong, "Effect of a fault and weak plane on the stability of a tunnel in rock-a scaled model test and numerical analysis," International Journal of Rock Mechanics and Mining Sciences, vol. 41, supplement 1, pp. 658-663, 2004.

[6] F. Huang, H. Zhu, Q. Xu, Y. Cai, and X. Zhuang, “The effect of weak interlayer on the failure pattern of rock mass around tunnel-scaled model tests and numerical analysis," Tunnelling and Underground Space Technology, vol. 35, pp. 207-218, 2013.

[7] F. Gao, K.-P. Zhou, W.-J. Dong, and J.-H. Su, "Similar material simulation of time series system for induced caving of roof in continuous mining under backfill," Journal of Central South University of Technology, vol. 15, no. 3, pp. 356-360, 2008.

[8] Y.-J. Li, X.-S. Li, G.-Z. Yin, and J.-W. Yao, "Similar material experimental study on the "domino effect" of the stope pillar unstable failure of gently inclined and medium thick phosphate rock under pillar and room caving," Disaster Advances, vol. 5, pp. 77-82, 2012.

[9] X. Li, Y. Li, M. Wang, and J. Wang, "Similar material experimental study on the deformation behavior of overburden rocks and mining pressure of the deep ore body of mining of Yunnan phosphate chemical group CO., LTD," Disaster Advances, vol. 6, pp. 363-369, 2013.

[10] M. A. Meguid, O. Saada, M. A. Nunes, and J. Mattar, "Physical modeling of tunnels in soft ground: a review," Tunnelling and Underground Space Technology, vol. 23, no. 2, pp. 185-198, 2008.

[11] W.-P. Fei, L. Zhang, and R. Zhang, "Experimental study on a geo-mechanical model of a high arch dam," International Journal of Rock Mechanics and Mining Sciences, vol. 47, no. 2, pp. 299-306, 2010.

[12] S.-C. Li, Y. Zhou, L.-P. Li et al., "Development and application of a new similar material for underground engineering fluidsolid coupling model test," Chinese Journal of Rock Mechanics and Engineering, vol. 31, no. 6, pp. 1128-1137, 2012.

[13] B.-C. Zuo, C.-X. Chen, C.-H. Liu, Q. Shen, G.-F. Xiao, and X.-W. Liu, "Research on similar material of slope simulation experiment," Rock and Soil Mechanics, vol. 25, no. 11, pp. 18051808, 2004.

[14] Y. Zhang, X. Wang, Q. Liang, D. Jiang, and X. Ma, "Development of model test similar material of collapsible loess," Chinese Journal of Rock Mechanics and Engineering, vol. 32, no. 2, pp. 4019-4024, 2013.

[15] W. Hui, X. Jian, G. Yu-Kun, and H. Qi-qi, "Similarity criterion analysis of goaf similar material simulation," in Proceedings of the International Colloquium on Safety Science and Technology, vol. 34, pp. 11-14, Shenyang, China, 2012.

[16] L. C. Dai, "Research on simulation test of coal similar material," Advanced Materials Research, vol. 850-851, pp. 847-850, 2014. 

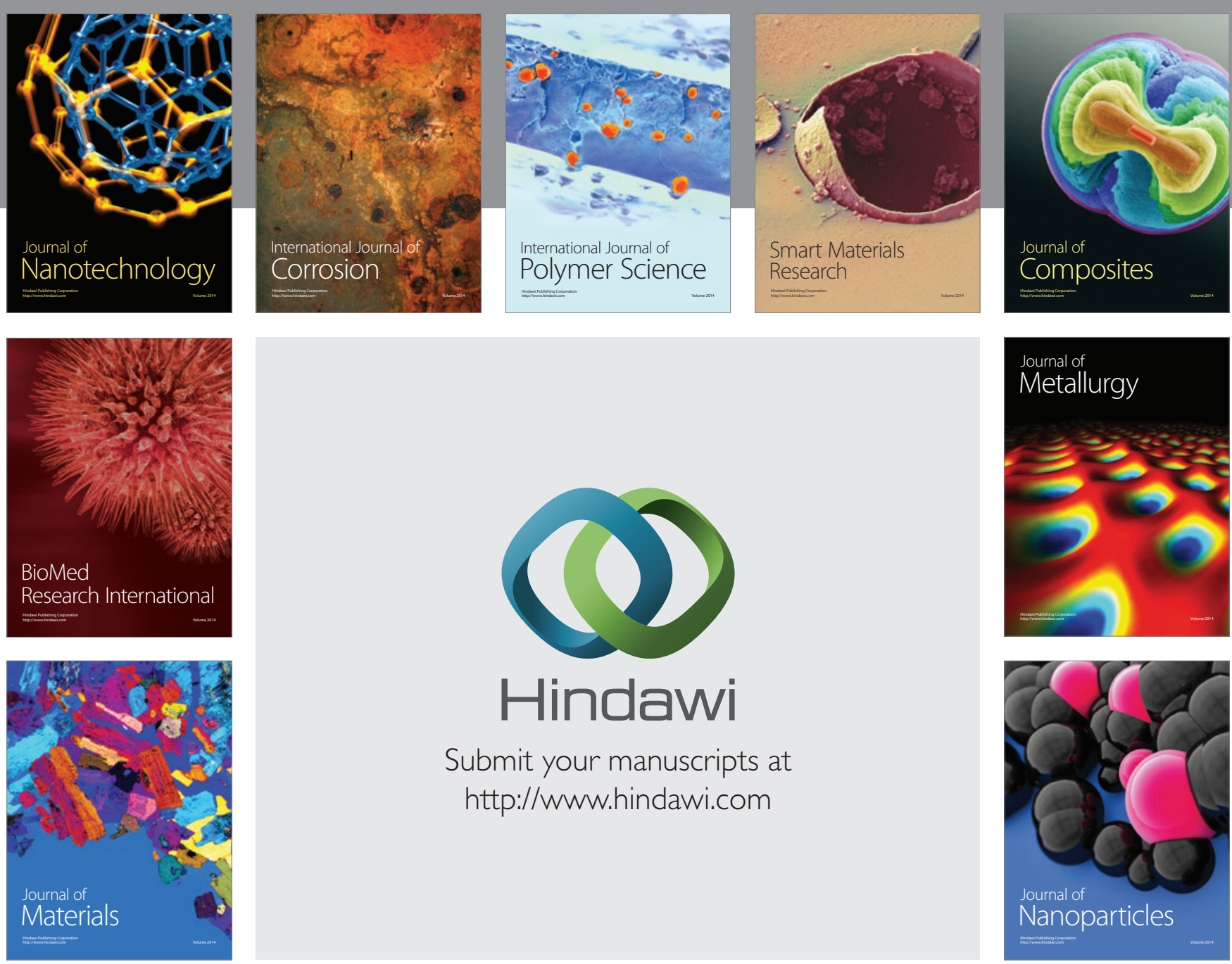

Submit your manuscripts at http://www.hindawi.com
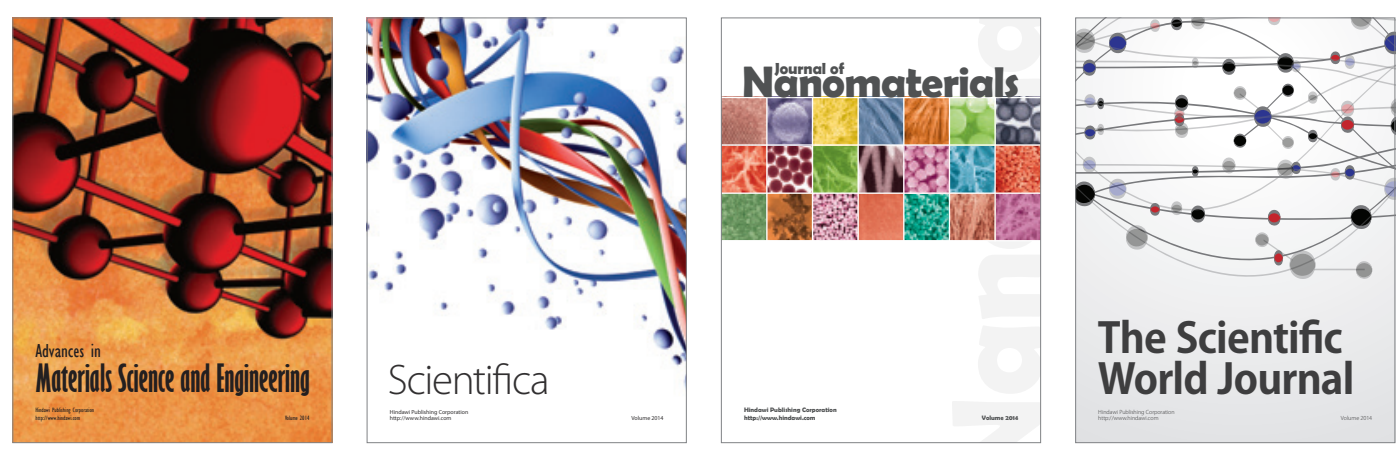

\section{The Scientific World Journal}
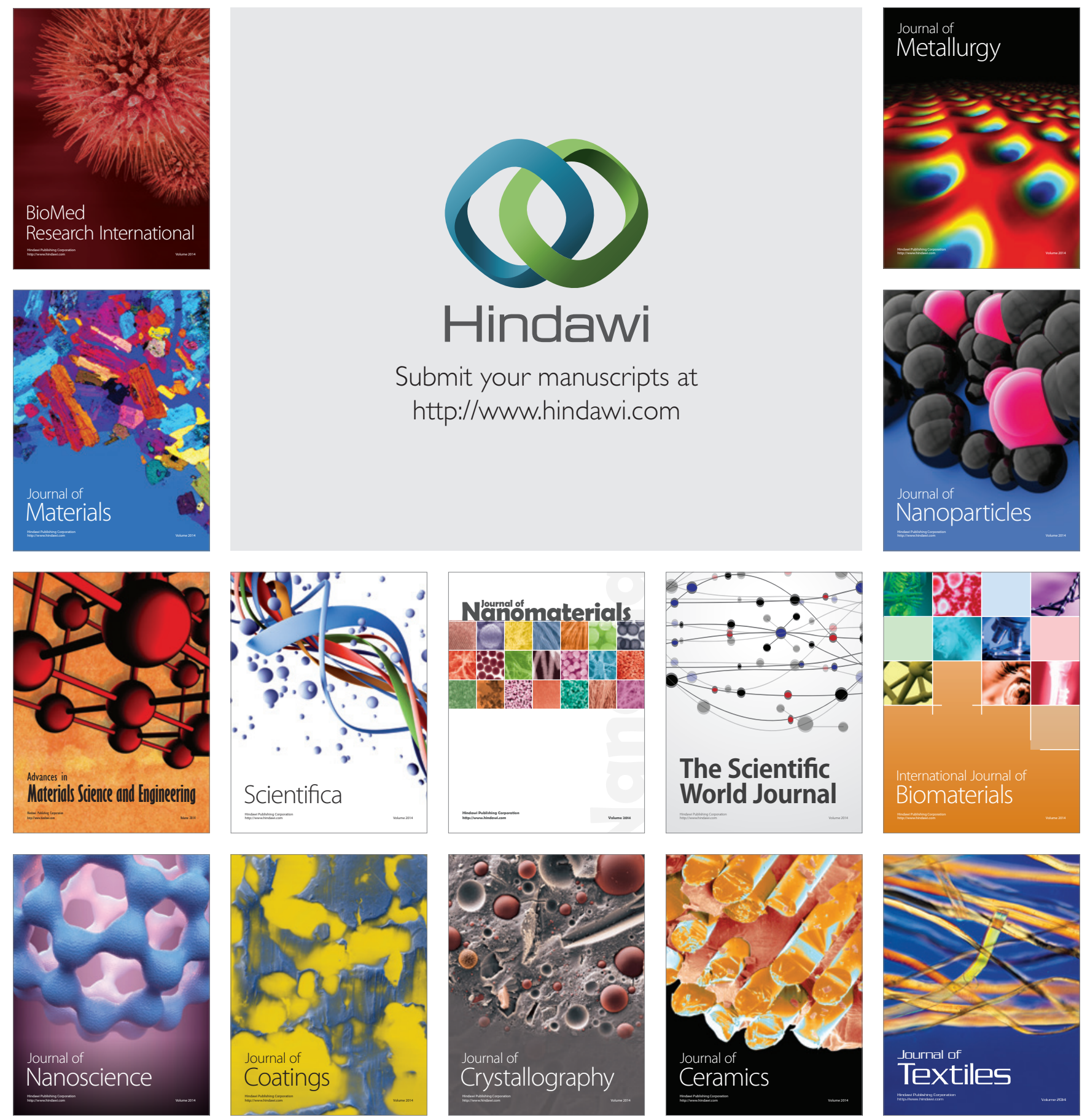